\title{
Teacher Questioning: Exploring Student Interaction and Cognitive Engagement in Spanish and EMI University Lectures
}

\author{
DAVINIA SÁNCHEZ-GARCÍA \\ Universidad Complutense de Madrid
}

Received: $9^{\text {th }}$ April 2018 / Accepted: 14 ${ }^{\text {th }}$ April 2018

ISSN: $1697-7467$

\begin{abstract}
This paper reports on the findings of a contrastive study exploring the use of teacher questions to gauge their cognitive demand and potential for triggering interaction between classroom participants. The data consists of a corpus of 16 lectures given in Spanish and English (eight of each) from two subjects in a Business Administration degree. Results show similarities and differences in the use of teacher questions in Spanish and EMI contexts, and highlight the importance of language awareness to help lecturers notice the impact of their discourse on students' learning.

Keywords: questions, interaction, EMI, higher education, classroom discourse, teacher training.
\end{abstract}

Las preguntas de los profesores: interacción e implicación cognitiva en el alumnado en clases impartidas en L1 y EMI en educación superior

RESUMEN: Este estudio informa de los resultados de un análisis contrastivo que explora el uso de las preguntas como recursos lingüísticos del profesor e investiga su potencial para fomentar la interacción y el desarrollo cognitivo de los alumnos. Para ello se analizan 16 clases del Grado de ADE impartidas tanto en español como en inglés. Los resultados reflejan similitudes y diferencias en el uso de las preguntas según la lengua de instrucción y destacan la importancia de concienciar a los profesores del posible impacto de su discurso en el aprendizaje de sus alumnos.

Palabras clave: preguntas, interacción, educación superior, discurso del aula, formación del profesorado.

\section{InTRODUCTION}

A pressing need to adapt to a social context characterized by globalization is having a significant impact on universities. Nowadays, society increasingly requires more qualified and mobile professionals to be part of a much more competitive job market. This is prompting universities to move towards the attraction of fee-paying international students, gifted lecturers and researchers from around the world and talented postgraduates, not only for economic reasons, but also to boost the university's reputation and prestige (Ramos, 2013; Dafouz, 2015). Therefore, university faculties are characterized by a more international and heterogeneous composition, in turn leading to new needs such as the internationalization 
of the curriculum and the adoption of a lingua franca (typically English) as a means of communication in these educational contexts.

The Spanish system is no exception. It has been influenced by specific educational and linguistic European policies seeking member states' unification (Pavón \& Ellison, 2013: 67) and is witnessing a spread of teaching and learning academic contents through second languages (L2s), predominantly English, throughout all educational levels.

Implementing English-medium instruction (EMI) brings with it a number of challenges, including the fact that teachers now find themselves having to interact, negotiate, co-construct meaning and explain content in a language that is neither their L1, nor, often, the L1 of most of the students, or even the language spoken outside the academic context. This seems to have direct implications in the teaching and learning processes - since language provides access to academic knowledge and skills while disciplinary content provides the context for language to be conveyed (Lorenzo, 2007). In this equation, language use in the classroom acquires great importance and, thus, empirical research is called for so as to shed some light on teacher discourse practices, possible linguistic difficulties when teaching through a L2 and potential measures to help them improve from this perspective.

Although research concentrating on classroom discourse is abundant in traditional EFL classroom contexts and, by extension in primary and secondary CLIL settings, less attention has so far been paid to the discourse needs that university lecturers embarking on EMI may be facing. A relevant study acknowledging such necessities was undertaken by Martín del Pozo (2014), whose study provided insights into the use of discourse markers and academic functions to highlight the importance of metalanguage to signal lectures phases and creating interactivity.

A further study was undertaken by Dafouz and Núñez (2010), who identified the type, function and linguistic realization of metadiscursive devices deployed in L1 and L2 lecture organization as part of teacher performance. They found that there was more explicit signposting, and a wider range of stylistic choices through the L1.

The present study sets out to throw some light on this research area by complementing and trying to go beyond previous research. In doing so, it will offer a contrastive analysis of Spanish and EMI and university contexts regarding the possible similarities and differences in teacher questioning practices. It will, more specifically, focus on the extent to which teacher questions enhance students' cognitive engagement and active participation in content subject lectures and on examining whether there is any variation in these two aspects depending on the language of instruction (L1 or L2) in which questions are formulated. To this aim, the following research questions are posed:

RQ 1. To what extent does the use of questions by teachers promote interaction between classroom participants in L1 and EMI settings?

RQ 2. To what extent does the use of questions by teachers engage students cognitively in L1 and EMI settings?

Before displaying the results obtained in the analysis and the pedagogical conclusions reached, the importance of the interaction triggered by teacher questions in the teaching and learning processes and specific information about the methodology followed in the study are detailed. 


\section{THEORETICAL FRAMEWORK}

\subsection{The role of input, interaction and output in the learning process}

Input is one of the most important concepts in second language acquisition (SLA) theories since no model has managed to explain the development of language in individuals without the presence of some sort of input. For this reason, research has always been concerned about the type of input that seems to be necessary for acquisition (Mitchell \& Myles, 2004). However, it has been claimed that not only the mere production of input but also its comprehension and the resulting interaction are responsible for language learning. Research seemed to confirm that interactional modifications deriving from negotiations for meaning turn out to be very effective in promoting comprehension of input (Saville-Troike $\&$ Barto, 2016). The power of interaction in learning resides in the fact that it requires, firstly, the decoding and understanding of the incoming input and, secondly, the production of output as a reaction. It is commonly claimed that comprehensible output may even be more important to learning than comprehensible input (Swain, 2000; Dalton-Puffer \& Smit, 2007).

Although these are SLA theories, the present study argues that their claims and implications hold true even if the 'object' of learning changes. In university instruction, the learning aim is placed on the knowledge of academic disciplines. This is equally true in EMI at university, where there is no explicit focus on developing the language competence of students who learn subject matter through English; although this does not mean that L2 competence is not acquired through the practice of constructing and negotiating meaning (Doiz et al., 2013; Dafouz, Hüttner \& Smit, 2016). While teachers are not the only sources of information, they are frequently the prime providers of language input in the class. And disciplinary content is realized, expressed and negotiated through language as it is realized in it. Therefore, teacher discourse and the way lecturers make use of language in class is crucial for knowledge to reach students effectively and to facilitate its subsequent comprehension and learning. For this reason, teachers become classroom models, providing content and language through comprehensible (and potentially enhanced) input (Moore 2007) and the agents responsible for managing the classroom as a social event, and promoting interaction and students' production of comprehensible output.

\subsection{Interaction as a social process of meaning-making}

Interest in interaction is not confined to SLA. Socio-cultural theory emphasizes the role played by the social context in which an interaction develops. This model views learning as the merging of an external-social plane and an internal-psychological one (Lantolf \& Poehner, 2014; Van Compernolle, 2015). It argues that successful learning is attainable through a guided process involving an eventual transition from inter-mental to self-governing activity. Before an individual becomes self-sufficient in terms of cognitive functioning, there is a necessary reliance on a more expert or knowledgeable person who provides instruction through collaborative learning. Eventually the less skilled individual becomes capable of taking over that knowledge and/or skills and internalizing them. 
Central to this theory is also the belief that the biological factors which lay the ground for human cognitive functioning are not sufficient to account for learning and thinking processes (Vygotsky, 1989). In addition, human thinking is mediated by culturally constructed tools. Thus, the process of teaching and learning at tertiary education (as at any other educational level) can be regarded as a culturally-specific situated activity (Lave \& Wenger, 1991). And it is language that mediates the learning process that results from and in the communicative interaction that leads to the development of linguistic, conceptual and cognitive skills.

This line of thought makes it possible to claim that it is by means of the constructive process inherent in interaction that learning will be attained. It is then considered of great importance to provide enough classroom space for negotiations of meaning between participants since these communicative exchanges may trigger students' development. They will allow learners to be engaged with ideas and concepts while fostering deeper and more diverse interpretations and understandings of disciplinary language and content as both interpsychological and intra-psychological processes. Here is where teachers become powerful agents in students' learning process, their discourse is the paramount tool mediating in its development.

\subsection{Teacher questions as triggers of interaction}

Among the numerous features of language comprising teacher talk, this study underlines questions as linguistic devices that are precisely capable of triggering such meaningful interaction between classroom participants; thereby possibly influencing the quantity and quality of students' potential learning.

Questions have been the object of study for a long time and have been analysed as syntactic, semantic, pragmatic and discursive categories. This has led to a number of different taxonomies attempting to classify them and explore their forms and functions (Dalton-Puffer, 2007; Chang, 2012; Sánchez-García, 2016). The present paper posits them as pivotal discourse tools, which articulate classroom talk as part of the linguistic repertoire of the teacher. They create and shape classroom interactional patterns by bringing together teachers' input and students' output. At the same time, they are likely to stimulate the use of a wide range of cognitive processes and may also scaffold students' development of conceptual and linguistic understanding. Questions also seem to support students' learning process by building collaborative meaning-making, ease students' comprehension of the lecture, elicit information, evaluate students' understanding and confront possible communicative breakdowns (Dafouz \& Sánchez-García, 2013), to name but a few functions. Therefore, for all this potential, effective teacher questioning is likely to be a powerful discourse strategy to enrich classroom climate and enhance both teaching and learning processes.

Classroom talk tends to be full of questions. However, although all teachers make use of them, few may be really aware of how they actually employ them or of how they could exploit them more effectively for the benefit of their teaching. This is likely true in monolingual (L1) teaching and doubly so in bilingual teaching. Becoming aware of questioning practices may be even more significant in teaching scenarios where conversational interactions need to be realized through a lingua franca. 


\section{Methodology}

\subsection{Context and participants}

This research is concerned with teachers' use of questions as a fundamental discourse feature which articulates classroom interaction and, therein, disciplinary negotiations of meaning among participants. Under these circumstances, this contrastive study attempts to gain new insights into classroom practices by combining a predominantly qualitatively analysis with a quantitative perspective.

The focal participants are two university lecturers teaching content subjects belonging to a Business Administration degree offered at a Spanish university. Lecturer A teaches Consumer Behaviour (CB), and Lecturer B teaches Financial Accounting (FA). Both lecturers teach their courses in two parallel groups: One given through Spanish (the L1 of most classroom participants), and the other taught through English (an L2 for the teacher and most students). These classes provide an opportunity to analyse how the same content is negotiated. In this context, the language of communication is the main research variable; other factors such as content, dynamics, materials and evaluation criteria remain relatively stable. While both teachers have a $\mathrm{C} 1$ level (CEFR) of English, their teaching experience differs. At the time of the study, Lecturer A had been teaching CB for three years in both language groups and Lecturer B had been teaching FA in Spanish for fourteen years and in English for five.

\subsection{Data collection and analysis}

The corpus collected (Table 1) consists of 16 lectures, which are divided into two subsets of 8 classes - each subset given by one of the two lecturers. The disciplinary contents of the 8 lectures within each subset are the same, which makes them comparable to one another. All lectures differ in length and word count, but the means are included for comparative purposes. The overall data accounts for 1,305 minutes of teaching practice and a total number of 152,530 words. ${ }^{1}$

The lectures were recorded, videotaped and later manually transcribed using the framework proposed by Du Bois et al. (1993). For analytical purposes, questions were initially identified on the basis of three features: i) syntactic form, ii) intonation and iii) utterance function. Some questions proved to be clearly multifunctional and this gave rise to a further, more context-sensitive, analysis. Therefore, questions were identified, tagged and classified in two different and separate coding processes.

1 Results have been normalized (\%) for comparative purposes. 
Table 1. Data collection

\begin{tabular}{|c|c|c|c|c|c|}
\hline & & Lecture & Topic & Minutes & Words \\
\hline \multirow{9}{*}{$\begin{array}{l}\text { L1 (Span- } \\
\quad \text { ish) }\end{array}$} & \multirow{4}{*}{$\begin{array}{c}\text { Lecturer } \\
A\end{array}$} & 1 & Actitudes en la publicidad & 81 & 11172 \\
\hline & & 2 & $\begin{array}{l}\text { Motivación del consumidor e influen- } \\
\text { cias de la familia en la publicidad }\end{array}$ & 88 & 13189 \\
\hline & & 3 & Influencias sociales en la publicidad & 87 & 12892 \\
\hline & & 4 & La clase social en la publicidad & 65 & 9386 \\
\hline & \multirow{4}{*}{$\begin{array}{c}\text { Lecturer } \\
B\end{array}$} & 5 & La cuenta de pérdidas y ganancias & 101 & 14080 \\
\hline & & 6 & Seminario: base de datos SABI & 52 & 6082 \\
\hline & & 7 & Hechos contables y libros contables & 95 & 12576 \\
\hline & & 8 & $\begin{array}{l}\text { Libros contables: el diario y el libro } \\
\text { mayor }\end{array}$ & 65 & 7811 \\
\hline & & & Total L1 & 634 & 87188 \\
\hline \multicolumn{4}{|c|}{ L1 Mean length time and number of words } & 79.25 & 10898.5 \\
\hline \multirow{9}{*}{$\begin{array}{c}\text { L2 } \\
\text { (English) }\end{array}$} & \multirow{4}{*}{$\begin{array}{c}\text { Lecturer } \\
A\end{array}$} & 1 & Attitudes in advertising & 85 & 7037 \\
\hline & & 2 & Consumer motivations in advertising & 86 & 7841 \\
\hline & & 3 & $\begin{array}{l}\text { Family and social influences in adver- } \\
\text { tising }\end{array}$ & 78 & 7894 \\
\hline & & 4 & Social class in advertising & 72 & 8872 \\
\hline & \multirow{4}{*}{$\begin{array}{c}\text { Lecturer } \\
B\end{array}$} & 5 & The income statement & 101 & 8637 \\
\hline & & 6 & Seminar: SABI database & 46 & 4295 \\
\hline & & 7 & Book keeping & 99 & 10054 \\
\hline & & 8 & $\begin{array}{l}\text { Accounting books: the journal and the } \\
\text { ledger }\end{array}$ & 104 & 10712 \\
\hline & & & Total L2 & 671 & 65342 \\
\hline \multicolumn{4}{|c|}{ L2 Mean length time and number of words } & 83.875 & 8167.75 \\
\hline \multicolumn{4}{|c|}{ Overall total } & 1305 & 152530 \\
\hline
\end{tabular}

By their defining nature, not all questions provide space for replies. Such is, for instance, the case of self-answered and rhetorical questions (Sánchez-García, 2016). The former tend to be immediately answered by the teachers themselves, thus preventing any response from the students. Similarly, the latter are typically posed for reflection, and so an actual followup may not be expected. Considering this and bearing in mind that this study focuses on classroom interaction, only those questions that gave students the opportunity to contribute with a response were identified and considered for analysis.

Three principle question categories, characterized by their original interactional nature, were scrutinized in this study: Confirmation checks, display and referential questions. On 
the one hand, confirmation checks include those questions aiming at ensuring students' understanding of the lecture (e.g. "Ok?", "Do you understand?", "Pardon?", "Excuse me, what do you mean by that?", "Did you say...?"). On the other hand, display and referential questions differentiate whether the teacher asking the question actually knows the answer to it, in which case the question will be display (e.g. "What are the differences between annual report and financial statement?"), or whether the answer is unknown to the teacher in which case the question will be referential (e.g. "What sorts of ideas have you come up with?").

These questions were further classified, as previously explained, regarding their cognitive load. For this purpose, Dalton-Puffer's taxonomy (2007) served as the analytical tool. This model ranks questions according to their cognitive complexity, considering whether they require lower or higher cognitive skills to answer them (see Figure 1). For instance, a question which calls for a fact will place a lower cognitive load on students than asking them to develop reasoning.

Figure 1. Complexity ranking of questions / responses (adapted from Dalton-Puffer, 2007: 118)

\begin{tabular}{|l|l|}
\hline Metacognitive & \\
Reason & \\
Explanation & COGNITIVE \\
Description & LOAD \\
Opinion & \\
Facts & \\
\hline
\end{tabular}

\section{Questions AS TRIgGers OF INTERACTION AND COGNITIVE ENGAGEMENT: RESULTS AND DISCUSSION}

Given the importance of involving students in meaningful negotiations of meaning to enhance their linguistic, conceptual and cognitive engagement with the discipline knowledge, this study analyzes teacher questions as potential triggers of such interaction. Confirmation checks will be the first question category to be examined, followed by the display-referential dichotomy.

\subsection{Confirmation Checks}

Confirmation checks have often received research attention, especially within the area of SLA (Long, 1980; Pica, 2005), for their potential interactive nature and their key role in negotiations of meaning. Through their use, classroom participants engage in meaningful talk in the quest to check and, ultimately, achieve mutual comprehension of the topic at hand.

Findings of a previous study on this topic (Dafouz \& Sánchez-García, 2013) seem to confirm that university lectures are particularly rich in confirmation checks. The assumption would naturally be that the prime function of checks would be to ascertain whether the 
audience is following the unfolding speech. However, a closer examination of the data collected makes it possible to argue that confirmation checks tend to lose this potential purpose and often work as automatized words that seem void of meaning:

(1) T: ¿Qué? No te he entendido

S: Que se intenta romper la creencia que se tiene hacia que el Lidl es barato

T: ¿Eso tratan de hacer?

S: Tratan

T: ¿Tratan?

S: Sí

T: ¿Sí?

$\mathrm{S}$ : Yo creo que lo que es más caro tiene que ser mejor

(2) Lidia, do you follow me?

S: Yes

T: Really? So a revenue is a temporary or a permanent account?

S: Temporary

In example 1 and 2 instances of the prototypical function of confirmation checks are displayed. As can be seen, they produce a negotiation of meaning between the lecturer and the students and seem to be produced to clarify and confirm facts so as to reach a final agreement on the two parts. However, although this is the archetypal use of such interrogative mechanisms, evidence seems to prove that it is not always rule of thumb and that another major function is also realized by confirmation checks:

(3) La contabilidad no se aprueba el último día, ¿vale? Pronto vamos a hacer un test sorpresa, ¿vale? Los ingresos y los gastos son aumentos y disminuciones de patrimonio neto. Es decir que sólo tenemos tres masas: activo, pasivo y patrimonios netos, ¿vale? Y la cuenta de pérdidas y ganancias la tenemos en el balance de situación, ¿vale?

(4) We are going to learn how to record the transaction in a company. Ok? We cannot record all the thing that happen in a firm. We are going to record only the accounting event, ok? We are going to learn the different books of accounting: the journal and the ledger. We are going to understand the rule of debit and credit, entries and then the logic of transaction. Ok?

In contrast with instances 1 and 2, in examples 3 and 4 , lecturers employ confirmation checks but continue speaking without providing any thinking time or space for students to answer and corroborate understanding (or not). Lecturers are likely to utter them as discourse devices that would typically mark a speech boundary and that grant the speaker some extra time to ponder the ongoing discourse. This may signal a mechanized use of these apparently instinctive structures, which leads to argue that, more often than not, confirmation checks tend to lose their potential function to arrive at mutual comprehension, instead functioning as filler expressions. 
Obviously, this finding demonstrates that confirmation checks are not always triggers of interaction. As illustrated in Table 2, confirmation checks that do not trigger any contribution from the students tend to outnumber those which do generate communicative exchanges in all lectures, regardless of the language used as vehicle of instruction. Yet, interestingly, EMI lectures are often the contexts in which this question category stimulates more negotiations of meaning among classroom participants.

Table 2. Confirmation checks triggering interaction (n)

\begin{tabular}{|c|c|c|c|c|}
\cline { 3 - 5 } \multicolumn{2}{c|}{} & $\begin{array}{c}\text { Total } \\
\text { Confirmation } \\
\text { Checks }(n)\end{array}$ & $\begin{array}{c}\text { Triggering } \\
\text { Interaction (n) }\end{array}$ & $\begin{array}{c}\text { Interaction } \\
\text { Triggered (\%) }\end{array}$ \\
\hline Lecturer $A(C B)$ & L1 lectures & 408 & 118 & 28.92 \\
\hline & EMI lectures & 218 & 112 & 51.37 \\
\hline Lecturer B (FA) & L1 lectures & 587 & 51 & 8.68 \\
\hline & EMI lectures & 623 & 76 & 12.19 \\
\hline
\end{tabular}

When looking at the figures in Table 2, it can be observed that only $28.92 \%$ of the confirmation checks uttered in CB L1 lectures (Lecturer A) pave the way for an actual interactive move between participants; while the tendency is higher in the EMI lectures of the same subject, in which more than half of all confirmation checks occurring $(51.37 \%)$ end up in interaction. When it comes to the FA lectures, figures decline notably. Only $12.19 \%$ of confirmation checks in the EMI lessons generates students' contributions, and a scarce $8.68 \%$ of them do the same in the L1 classes. Results then clearly bring into evidence that EMI lectures are more likely to witness student responses to confirmation checks. Besides, the data seems to suggest that since negotiations take place through a L2, the lecturer is likely to feel the need to verify whether students are reaching content comprehension or not. The use of confirmation checks highlights a reinforced commitment from the lecturer to get feedback on learner understanding more often than when they communicate through their L1. This is illustrated in example 5, where the teacher utters several confirmation checks seeking validation from the student and waits for any possible reply. However, as responses are not verbalized, she addresses a student personally and does not cease her efforts to confirm once more.

(5) T: We have used our right to pay money. Now we have already collect money. Ok? Yes? (...3) Questions? Daniel, you don't have any questions?

S: No

T: Do you follow?

S: Yes

T: Yes? Ok

Such negotiation instances report yet another interesting revelation. It seems that teachers' use of confirmation checks do trigger students' thinking processes although not necessarily verbal ones. Possibly hoping to be interrupted if the learners ever encounter any difficulty, they do not provide time for students' answers. So, confirmation checks could likewise work as indirect invitations and allowances to talk wherever needed. 
Overall, it seems that although confirmation checks present the prime function of engendering interaction among classroom participants, unexpectedly they are not sufficiently exploited for that purpose. The question remaining here then is whether teachers do not consciously seek that interaction or whether they do and actually think that they are sparking interaction by using such questions without realizing that the way they produce them often blocks that potential for student engagement in interaction.

\subsection{Display and Referential Questions}

It is true that opportunities for interactional moves in the classroom are not contingent on the teacher exclusively. On a number of occasions, no output is generated by students despite lecturers' successful use of questions. However, students' opportunities to interact, to a great extent, seem to be largely influenced by how lecturers articulate questions, as the formulation of confirmation checks has already shown. Under these circumstances, it seems compelling to look into the relationship between teachers' questions and students' replies as derived from teacher's display and referential questions (see Table 3).

Table 3. Number of questions (Qs) and interaction triggered (TI) (n)

\begin{tabular}{|c|c|c|c|c|c|c|c|c|}
\hline \multirow[b]{3}{*}{ Lecture } & \multicolumn{4}{|c|}{ Lecturer A - L1 lectures } & \multicolumn{4}{|c|}{ Lecturer A - EMI lectures } \\
\hline & \multicolumn{2}{|c|}{ Referential } & \multicolumn{2}{|c|}{ Display } & \multicolumn{2}{|c|}{ Referential } & \multicolumn{2}{|c|}{ Display } \\
\hline & $Q s$ & $T I$ & $Q s$ & $T I$ & $Q s$ & $T I$ & $Q s$ & $T I$ \\
\hline 1 & 57 & 30 & 45 & 20 & 64 & 32 & 29 & 14 \\
\hline 2 & 28 & 17 & 61 & 36 & 46 & 17 & 6 & 5 \\
\hline 3 & 81 & 48 & 24 & 12 & 36 & 21 & 33 & 17 \\
\hline 4 & 56 & 24 & 15 & 9 & 36 & 21 & 17 & 5 \\
\hline \multirow[t]{5}{*}{ Total } & 222 & 117 & 145 & 71 & 182 & 91 & 85 & 41 \\
\hline & \multicolumn{4}{|c|}{$367 / 188$} & \multicolumn{4}{|c|}{267 / 132} \\
\hline & \multicolumn{4}{|c|}{ Lecturer B - L1 lectures } & \multicolumn{4}{|c|}{ Lecturer B - EMI lectures } \\
\hline & \multicolumn{2}{|c|}{ Referential } & \multicolumn{2}{|c|}{ Display } & \multicolumn{2}{|c|}{ Referential } & \multicolumn{2}{|c|}{ Display } \\
\hline & $Q s$ & $T I$ & $Q s$ & $T I$ & $Q s$ & $T I$ & Qs & $T I$ \\
\hline 1 & 14 & 5 & 124 & 70 & 32 & 12 & 91 & 57 \\
\hline 2 & 4 & 3 & 25 & 9 & 2 & 2 & 14 & 7 \\
\hline 3 & 11 & 7 & 98 & 64 & 10 & 4 & 121 & 72 \\
\hline 4 & 9 & 2 & 166 & 122 & 10 & 5 & 100 & 80 \\
\hline \multirow[t]{2}{*}{ Total } & 38 & 17 & 413 & 265 & 54 & 23 & 326 & 216 \\
\hline & \multicolumn{4}{|c|}{$451 / 282$} & \multicolumn{4}{|c|}{$380 / 239$} \\
\hline
\end{tabular}


Analysis of the data shows that, on the one hand, just 188 out of 367 , (51.2\%), of display and referential questions taking place in the L1 CB classes end up triggering interaction; whereas only 132 out of $267,(49.4 \%)$ of these questions, allow a response from the students in the EMI CB lessons. On the other hand, 282 out of 451, (62.52\%) of display and referential questions, lead to interactional exchange in L1 FA lectures, and in turn, 239 out of $380,(62.89 \%)$ of the very same question types, are interactional in EMI FA classes.

From this may follow that asking a question does not always result in obtaining an answer. In other words, the number of questions produced by lecturers is not a transparent sign of classroom interaction. In fact, what seems to be quite clear is that lectures are scenarios that offer a very extensive number of opportunities for interaction derived from the formulation of questions, but merely half of them bear fruit. This finding calls for a more exhaustive analysis of the nature and actual use of teacher display and referential questions, firstly, in terms of the kind of interactional chances they provide students with and, secondly, in terms of the cognitive demand they place on students.

\subsubsection{Interaction triggered by display and referential questions}

The display-referential dichotomy has traditionally generated heated debate regarding which of the two categories is more effective for learning. Display questions aim at asking for already known information by all participants in a conversation and generally require short responses to very particular issues. Hence, they often seem to restrict responses and somehow limit students' output. For these reasons, this question type has always found detractors that often regard them as inhibitors of real communication. Conversely, referential questions are generally the most sought-after type of question. They typically resemble reallife communication as they ask for unknown information and, therefore, aim at generating meaningful communication. Due to this genuine interrogative nature, referential questions are believed to be better triggers of interaction as they lead to longer, more authentic and more personal answers from the students (Dalton-Puffer, 2007: 101). Despite these widely accepted assumptions, inspection of the data in this study reports that $25.77 \%$ of the questions are display questions and $12.92 \%$ are referential ones. Consequently, it is revealed that there seems to be a well-defined tendency to use a higher number of display questions instead of referential ones in all lectures (see Table 3). The educational context where these question types take place may have a say in this tendency. In the end, students' learning is the ultimate goal in class and teachers need to make sure that their students are acquiring knowledge. Therefore, the high frequency in verifying students' learning through display questions seems to be reasonable.

Still having to do with the defining nature of these two question categories, data reveal that the answers that display and referential questions elicit, although postulated as varying in length and grammatical complexity, are perhaps not so divergent: 
Table 4. Examples of display vs. referential questions

\begin{tabular}{|l|l|}
\hline \multicolumn{1}{|c|}{ Display questions } & \multicolumn{1}{c|}{ Referential questions } \\
\hline T: How many accounting books do we have? & T: I've seen you have brought several exam- \\
SS: [[Three]] & ples. What have you uploaded, Ana? \\
T: Three accounting books. The journal book, & S: An add about the Olympics \\
then...? & T: And you brought as an example of? \\
SS: [[Ledger]] & S: Of emotions \\
T: The ledger. & T: ¿A quién seguís en Twitter? \\
\hline \multirow{2}{*}{ Cuál no es actividad propia del } & S: Periódicos \\
negocio principal de mi empresa? & T: ¿Qué más páginas seguís? \\
S: Pago de intereses & S: Famosos, cantantes \\
T: ¿Por qué? & S: A futbolistas \\
S: Porque no es de explotación & T: Y, ¿eso es interesante? \\
& S: Sí \\
\hline
\end{tabular}

Table 4 contains instances of display and referential questions together with the answers that they elicit from the students. On the one hand, display questions consist of enquiries that ask about specific contents of the lecture, which makes it clear that their prime function is to test learners' knowledge, but principally focusing on particular factual concepts, definitions or clear-cut theoretical ideas. Consequently, students' limited answers seem to be good enough for the teacher's questioning purposes and, in fact, it seems that a minimal response is what lecturers are looking for. On the other hand, referential questions show how lecturers step out of classroom content and delve into students' individual opinions and personal thoughts. This is supposed to pave the way for more sophisticated and lengthy contributions, precisely because these questions address students' personally and allow more assorted replies, often promoting out-of-the-box critical thinking. Interestingly, students' output remains stagnant concerning referential enquiries and does not entail any observable change concerning length or verbal complexity when compared to the answers elicited by display questions. As a result, it could be claimed that teachers may not be making the most out of the potential offered by referential questions regarding the opportunities that they provide to generate meaningful negotiations among classroom participants.

After a closer examination of all the instances of referential questions, it could be argued that the fact that students' answers to referential enquiries tends to be confined to curtailed sentences is rooted in the characteristics of those questions. The study holds that although the display-referential dichotomy is mainly defined by whether answers to questions are known or unknown to the person asking, it is also largely determined by whether questions are open- or closed. Display enquiries tend to be closed in nature since they seek eliciting particular answers. Contrarily, referential questions are by their nature required to be open as they aspire to prompt more general, wider and freer replies. Despite this, in the lectures analyzed referential enquiries belie their true nature, since the majority of them are found to be closed. 
D. SÁNCHEZ-GARCía Teacher Questioning: Exploring Student Interaction and Cognitive Engagement

Table 5. Open- and closed-ended questions (n)

\begin{tabular}{|c|c|c|c|c|c|c|c|c|}
\hline & \multicolumn{4}{|c|}{ Lecturer A - L1 lectures } & \multicolumn{4}{|c|}{ Lecturer A - EMI lectures } \\
\hline & \multicolumn{2}{|c|}{$\begin{array}{c}\text { Referential } \\
\text { questions }\end{array}$} & \multicolumn{2}{|c|}{ Display questions } & \multicolumn{2}{|c|}{$\begin{array}{c}\text { Referential } \\
\text { questions }\end{array}$} & \multicolumn{2}{|c|}{ Display questions } \\
\hline & Open & Closed & Open & Closed & Open & Closed & Open & Closed \\
\hline Lecture 1 & 17 & 40 & 8 & 37 & 24 & 40 & 15 & 14 \\
\hline Lecture 2 & 4 & 24 & 11 & 50 & 16 & 30 & 1 & 5 \\
\hline Lecture 3 & 34 & 47 & 9 & 15 & 11 & 25 & 6 & 27 \\
\hline Lecture 4 & 12 & 44 & 3 & 12 & 5 & 31 & 5 & 12 \\
\hline \multirow[t]{5}{*}{ Total } & 67 & 155 & 31 & 114 & 56 & 126 & 27 & 58 \\
\hline & \multicolumn{4}{|c|}{367} & \multicolumn{4}{|c|}{267} \\
\hline & \multicolumn{4}{|c|}{ Lecturer B - L1 lectures } & \multicolumn{4}{|c|}{ Lecturer B - EMI lectures } \\
\hline & \multicolumn{2}{|c|}{$\begin{array}{c}\text { Referential } \\
\text { questions }\end{array}$} & \multicolumn{2}{|c|}{ Display questions } & \multicolumn{2}{|c|}{$\begin{array}{l}\text { Referential } \\
\text { questions }\end{array}$} & \multicolumn{2}{|c|}{ Display questions } \\
\hline & Open & Closed & Open & Closed & Open & Closed & Open & Closed \\
\hline Lecture 1 & 3 & 10 & 35 & 85 & 14 & 13 & 37 & 56 \\
\hline Lecture 2 & 1 & 3 & 8 & 16 & 1 & 1 & 7 & 7 \\
\hline Lecture 3 & 3 & 6 & 21 & 76 & 4 & 5 & 17 & 100 \\
\hline Lecture 4 & 4 & 3 & 26 & 139 & 7 & 1 & 25 & 74 \\
\hline \multirow[t]{2}{*}{ Total } & 11 & 22 & 90 & 316 & 26 & 20 & 63 & 237 \\
\hline & \multicolumn{4}{|c|}{439} & \multicolumn{4}{|c|}{346} \\
\hline
\end{tabular}

Table 5 shows an increased presence of closed questions over open ones, irrespective of whether enquiries are display and referential. Therefore, it could be implied that the way teachers formulate questions may actually restrain students from contributing in extended discourse. 
Evidence shows that often the absence of verbal responses may be due to students' lack or uncertainty of knowledge. However, in most cases it is the teacher questioning practices which seem to impinge upon students' active contributions. It is common to find that the time restrictions imposed by the lecturer prevent learners from collaborating either because of insufficient wait time to grasp what is being asked and respond or because wait time does not exist at all.

In a similar vein, another common pattern that supports this finding is that teachers frequently produce chains of questions that end up limiting students' opportunities to talk. In example 6 Lecturer A demands students' participation by asking a chain of referential questions, but she moves from open-ended to closed-ended ones. Consequently, the options provided to students range from very open questions asking about their personal opinion to just a monosyllabic answer; once again closing the door to eventual interactions.

(6) T: So, what's the image you have of Benetton? Is it a brand for youngsters? Do you usually buy there? Do you do you shoppings? Do you go shopping to Benetton?

\section{S: Sometimes}

From all this it may be stated that despite learners not manifesting great enthusiasm for oral engagement in class and lecturers typically finding themselves grappling with this issue to foster participation, it may be the case that lecturers encumber themselves by not formulating questions effectively, steering them away from the target in mind. If lecturers introduce referential questions as a way to include learners' personal opinions and make the subject contents more approachable but they happen to be close-ended, the problem is likely to persist. The appropriate use of open referential enquiries could fuel brainstorms of ideas and the chances to negotiate meaning to thus promote students' involvement. For their part, display questions seem to be the right tool to verify content knowledge and, apparently, teachers use and formulate them without any seemingly difficulty.

\subsubsection{Cognitive Demand of Display and Referential Questions}

Apart from looking into the possibilities offered by questions for students' engagement in extended discourse, a further analysis to delve into the cognitive complexity that questions may demand has been carried out. Display and referential questions were further categorized along a continuum in which they range from being less to more complex in terms of cognitive load (see Figure 1 above).

$\mathrm{CB}$ lectures present a wider variety of cognitive questions when compared to FA classes. Yet, the bulk of questions asked in both subjects falls within the cognitively undemanding types (Figure 2 and 3). Lecturers' questions tend to primarily address disciplinary facts, although to a certain extent they also seem to rely on students' opinions. Asking for explanations and reasons is a quite scarce practice in these classes, and meta-cognitive questions barely take place. 
D. SÁNCHEZ-GARCÍA Teacher Questioning: Exploring Student Interaction and Cognitive Engagement

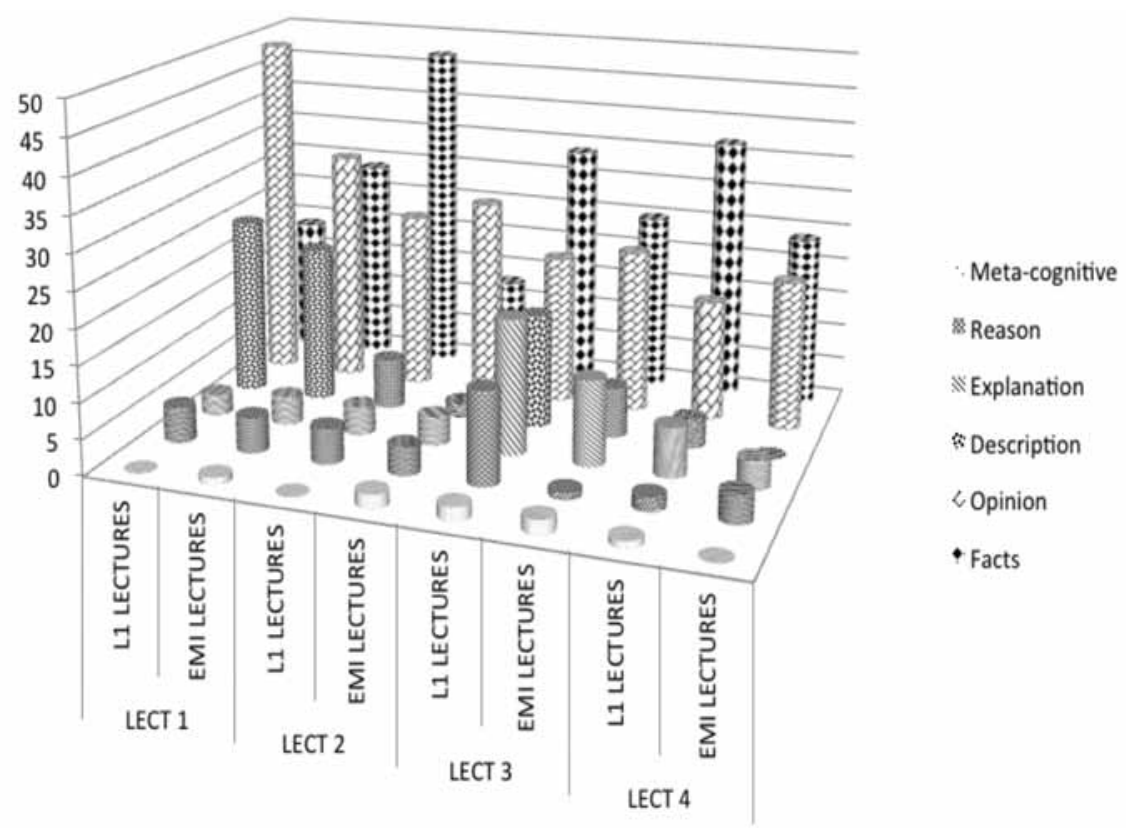

Figure 2. Cognitive scale in Lecturer A's questioning activity (n)

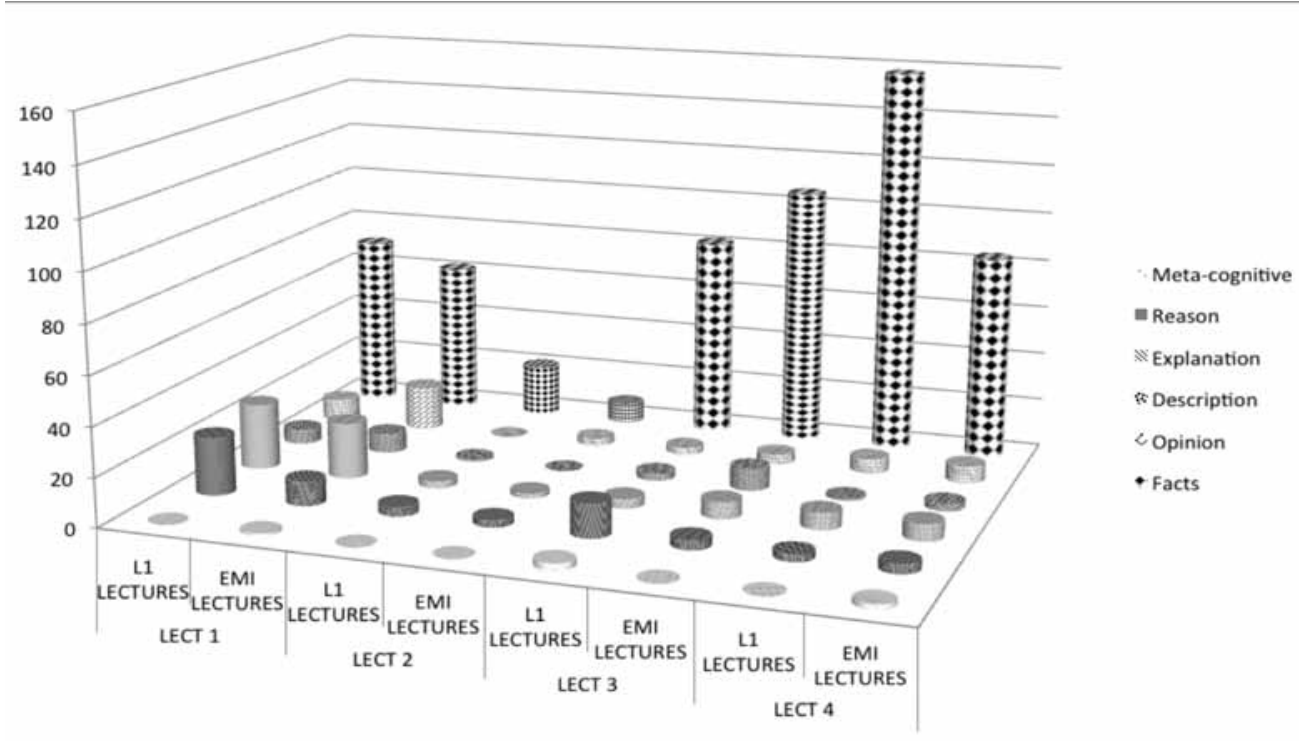

Figure 3. Cognitive scale in Lecturer B's questioning activity (n) 
It may then be concluded that questions could be better exploited as far as the cognitive effort that they place on students is concerned. Most of the teacher questions posed only require students to recall factual information, to navigate in a cognitively undemanding comfort zone. Teachers do not seem to be challenging learners to think and reason deeply, and to get involved with discipline knowledge as much as it seems to be possible. Promoting questions that address both lower- and higher- order thinking skills (Krathwolh, 2002) could lead to a much richer learning environment. Besides, enhancing the use of low and high cognitively demanding questions could likewise be an effective means of supporting students' learning and scaffolding their understanding by making knowledge linguistically and cognitively accessible (Sánchez-García, 2016).

\section{Conclusions AND PEDAgogical implications}

This study was posited on the assumption that questions are a pervasive teacher discourse strategy, potentially powerful triggers of meaningful classroom communicative exchanges. Concerning RQ1, results make it possible to claim that there appears to be no direct correlation between questions and interaction, as also suggested in other previous studies (SánchezGarcía, 2010; Dafouz \& Sánchez-García, 2013). The majority of the questions asked by lecturers tend to go unanswered, which signals missed opportunities regarding negotiation and co-construction of meanings. The factors that seem to lead to such lack of interaction range from student not knowing answers to teachers' unconscious prevention of replies. On the teacher front, this paper puts forward two measures that could improve this scenario: First, provision of longer wait time, so that students have more space to think and respond; and second, production of more effective open-ended questions, avoiding lecturers' question chains that narrow down students' opportunities for extended discourse.

Findings regarding RQ2 reveal that questions need to be further exploited in terms of cognition so that students have access to a wider range of cognitively demanding situations. Consequently, as teachers introduce the lecture and the difficulty of the content escalates, so could the cognitive complexity of questions to expose learners to an increasing learning challenge that would have a positive impact on the development of both their language and content knowledge and skills.

In addition, it has been discovered that questions tend to be deployed similarly in Spanish- and EMI contexts regarding both the cognitive demand and the interaction derived from their formulation. Under these circumstances it seems that questioning practices are likely to be determined, to a large extent, by the idiosyncrasy of the teachers and their personal discursive and teaching style and not only by their language use, which may be worthy of further study.

The main limitation of the research revolves around the fact that only two lecturers have been the object of study. This presupposes a cautious interpretation of the results since they cannot be generalized. For findings to have any real weight, the process would need to be repeated on a much larger scale.

As a final note, this research tries to contribute to teacher education by raising awareness of the relationship between questions, interaction and cognition within classroom discourse, 
and encouraging concrete measures that could be implemented. One of them could entail teachers' reflection of their own practice (Walsh \& Mann, 2015). Only in this way could lecturers be aware of their questioning strategies, the critical role they play, and what could be done to exploit them more effectively in both L1 and EMI educational contexts.

\section{REFERENCES}

Chang, Y. (2012). The use of questions by lecturers in lectures given in English: influences of disciplinary cultures. English for Specific Purposes, 31, 103- 116.

Dafouz, E. (2015). Más allá del inglés: la competencia lingüística multi-dimensional como estrategia para la enseñanza en la universidad internacional. Educación y Futuro, 32, 15-34.

Dafouz, E., \& Sánchez-García, D. (2013). 'Does everybody understand?' Teacher questions across disciplines in English-medium university lectures: an exploratory study. Language Value, 5(1), 129-151.

Dafouz, E., Hüttner, J., \& Smit, U. (2016). University teachers' beliefs of language and content integration in English-medium education in multilingual university settings, in T. Nikula, E. Dafouz, P. Moore, \& U. Smit (Eds.) Conceptualizing Integration in CLIL and Multilingual Contexts (pp.123-144). Bristol, England: Multilingual Matters.

Dalton-Puffer, C. (2007). Discourse in content and language integrated learning (CLIL). Amsterdam: John Benjamins Publishing.

Dalton-Puffer, C., \& Smit, U. (2007). Empirical perspectives on CLIL classroom discourse. Franktfurt, Vienna etc.: Peter Lang.

Doiz, A., Lasagabaster, D., \& Sierra, J.M. (2013). English-medium instruction at universities: global challenges. Multilingual Matters: Bristol.

Du Bois, J., Schuetze-Coburn, S., Cumming, S., \& Paolino, D. (1993). Outline of discourse transcription, in J. Edwards, \& M. Lampert (Eds.) Talking Data: Transcription and Coding in Discourse Research (pp. 45-89). Hillsdale, NJ: Lawrence Erlbaum.

Krathwohl, D. (2002). A revision of Bloom's taxonomy: an overview. Theory Into Practice, 41(4), 212-218.

Lantolf, J. \& Poehner, M. (2014). Sociocultural theory and the pedagogical imperative in L2 education: Vygotskian praxis and the research/practice divide. New York: Routledge.

Lave, J. \& Wenger, E. (1991). Situated learning: legitimate peripheral participation. Cambridge, UK: Cambridge University Press.

Long, M.H. (1980). Input, interaction and second language acquisition. (Published doctoral thesis). University of California, Los Angeles.

Lorenzo, F. (2007). The sociolinguistics of CLIL: language planning and language change in 21 st century Europe. RESLA, 1, 27-38.

Martín del Pozo, M.A. (2014). Aproximación lingüistico-didáctica al discurso académico de la clase magistral en la formación del profesorado universitario en contextos bilingües. (Unpublished doctoral thesis). Universidad Complutense de Madrid, Madrid, Spain.

Mitchell, R. \& Myles, F. (2004). Second language learning theories. London: Hodder Arnold.

Moore, P. (2007). Enhancing Classroom Discourse: a modelling potential for content teachers. In F. Lorenzo, S. Casal, V. Alba-Quinones and P. Moore, (Eds) Models and practice in CLIL. Revista española de lingüistica aplicada (RESLA) 20, Extra. 1: 141-152. 
Pavón, V. \& Ellison, M. (2013). Examining teacher roles and competences in Content and Language Integrated Learning (CLIL). Linguarum Arena, 4, 65-78.

Pica, T. (2005). Second language acquisition research and applied linguistics. Available at https:// repository.upenn.edu/gse _pubs/34, last accessed on 14 $4^{\text {th }}$ April, 2018.

Ramos, A.M. (2013). Higher education bilingual programmes in Spain. Porta Linguarum, 19, 101-111.

Sánchez-García, D. (2016). A contrastive analysis of Spanish- and English-medium instruction in tertiary education: teacher discourse strategies in a spoken corpus. (Unpublished doctoral thesis). Universidad Complutense de Madrid.

Sánchez-García, D. (2010). Classroom interaction in university settings: the case of questions in three disciplines. (Unpublished master's thesis). Universidad Complutense de Madrid, Madrid, Spain.

Saville-Troike, M., \& Barto, K. (2016). Introducing second language acquisition. Cambridge University Press.

Swain, M. (2000). The output hypothesis and beyond: mediating acquisition through collaborative dialogue, in J. Lantolf (Ed.) Sociocultural Theory and Second Language Learning (pp. 97-114). Oxford: Oxford University Press.

Van Compernolle, R. (2015). Interaction and second language development: a Vygotskian perspective. Amsterdam: John Benjamins.

Vygotsky, L. (1989). Thought and language. Cambridge, MA: MIT Press.

Walsh, S. \& Mann, S. (2015). Doing reflective practice: a data-led way forward. ELT Journal, 69(4), 351-362. 